\title{
Spinal Cord Blood Flow Measured with Microspheres Following Spinal Cord Injury in the Rat
}

\author{
M. Christopher Wallace and Charles H. Tator
}

\begin{abstract}
A decrease in spinal cord blood flow (SCBF) is a known sequela of spinal cord injury. The radioactive microsphere technique permits repeated measurement of spinal cord blood flow (SCBF) and cardiac output (CO) in the same experimental animal. The purpose of this study was to adapt the radioactive microsphere technique for use in the rat extradural clip compression injury model used in our laboratory.

Thirteen adult Wistar rats were anaesthetized and ventilated. Mean systemic arterial pressure (MSAP) was recorded continuously. Control animals $(n=8)$ did not have a surgical procedure whereas the injured animals $(n=5)$ underwent a C7-T1 laminectomy followed by a one minute, 50 gram extradural clip compression injury at T1. Radioactive microspheres were used for two blood flow and $\mathrm{CO}$ determinations in both groups.

MSAP fell $59 \%$ in the injured animals $(\mathrm{p}<0.01)$, but this was not accompanied by significant changes in heart rate or CO. There was a $50 \%$ reduction in SCBF in the injured cord $(p<0.02)$, and there were significant reductions in cerebral blood flow $(p<0.05)$ and cerebellar blood flow $(p<0.02)$ following spinal cord injury.
\end{abstract}

RÉSUMÉ: Le flot sanguin médullaire mesuré aux microsphères à la suite d'une blessure de la moelle épinière chez le rat Une diminution du flot sanguin médullaire est une séquelle bien connue de traumatisme à la moelle épinière. La technique utilisant des microsphères radioactives permet des mesures répétées du flot sanguin médullaire et du débit cardiaque chez le même animal d'expérimentation. Le but de cette étude était d'adapter la technique utilisant des microsphères radioactives, pour l'appliquer chez le rat utilisé dans notre laboratoire comme modèle animal de traumatisme par compression au moyen d'une pince extra durale.

Treize rats Wistar adultes furent anésthésiés et ventilés. La tension artérielle systémique moyenne fut enregistrée de façon continue. Les animaux contrôles $(n=8)$ n'eurent pas d'intervention chirurgicale, alors que les cas subirent une laminectomie au niveau de C7-T1, suivie d'une traumatisme par compression au moyen d'une pince extradurale exerçant une pression de $50 \mathrm{gm}$ pendant 1 minute au niveau de T1. Deux déterminations du flot sanguin et du débit cardiaque furent faites dans les deux groupes au moyen de microsphères radioactives.

La tension artérielle systémique moyenne chuta de $59 \%$ chez les animaux traumatisés, mais ceci ne fut pas accompagné de changements significatifs du rythme ou du débit cardiaque. Le flot sanguin médullaire fut réduit de $50 \%$ dans la moelle traumatisée $(\mathrm{p}<0.02)$ et le flot sanguin cérébral $(\mathrm{p}<0.05)$ et cérébelleux $(\mathrm{p}<0.02)$ furent réduits de façon significative à la suite du traumatisme médullaire.

Can. J. Neurol. Sci. 1986;13:91-96

A number of techniques have been utilized to measure spina! cord blood flow (SCBF) in experimental spinal cord injury. ${ }^{1-5}$ Techniques used in larger animals include the ${ }^{14} \mathrm{C}$-antipyrene method, ${ }^{1,3.6}$ the hydrogen clearance technique, ${ }^{2,4.5}$ and radioactive microspheres. ${ }^{7-10}$ The majority of investigations have demonstrated a drop in SCBF following experimental cord injury, ${ }^{1 \cdot 5.11}$ although hyperemia following cord injury has also been reported. ${ }^{2}$ In our laboratory, the experimental model has been clip compression injury in the rat, ${ }^{12}$ and SCBF was measured before and after injury by ${ }^{14} \mathrm{C}$-antipyrene autoradiography. ${ }^{1.3 .6}$ Although very accurate, this blood flow technique allows only one flow study per animal. In contrast, the radioac. tive microsphere method used by other investigators allows multiple studies per animal, ${ }^{7 \cdot 10}$ although only large animals such as dogs have been studied. Microspheres also allow measurement of regional organ blood flow, cardiac output (CO),

From the Division of Neurosurgery and Playfair Neuroscience Unit, Toronto Western Hospital, University of Toronto, Toronto. Ontario Received August 15, 1985. Accepted February 11, 1986.

Reprints requests to: C.H. Tator, M.D., Division of Neurosurgery, Playfair Neuroscience Unit, Toronto Western Hospital, 399 Bathurst Street. Toronto, Ontario, Canada M5T 2S8 
and distribution of $\mathrm{CO}$, and these parameters have been measured in the rat. ${ }^{13-24}$ However, to our knowledge, SCBF has not been measured in rats with radioactive microspheres.

The purpose of this experiment was to adapt the radioactive microsphere technique for SCBF studies in the rat and to apply the method to the measurement of SCBF, regional organ blood flow and $\mathrm{CO}$ before and after clip compression injury of the rat spinal cord.

\section{METHODS}

\section{Operative Procedure}

Thirteen female Wistar rats weighing 218 - 251 grams, were anaesthetized with sodium pentobarbital $(40 \mathrm{mg} / \mathrm{kg}$ intraperitoneally). A tracheostomy was performed, and the animals were mechanically ventilated. The right femoral artery and vein, and the right internal jugular vein were cannulated with PE50 tubing filled with heparinized saline $(10 \mathrm{IU} / \mathrm{ml})$. Two special catheters were made by heat-fixing a segment of PE 10 tubing to the end of a PE50 cannula. These catheters were subsequently placed into the left ventricle via a right common carotid arteriotomy, and into the abdominal aorta below the renal arteries via a left femoral arteriotomy. MSAP and arterial blood gases were monitored via the femoral artery cannula. MSAP was measured with a pressure transducer (Bell \& Howell, Model 4-327-101) coupled to a pressure amplifier (Hewlett Packard Model 8805c) and multi-channel recorder (Hewlett Packard Model $87758 \mathrm{c})$. The left ventricular pressure profile and central venous pressure (CVP) were measured with the same transducer and recorder. Arterial blood gases ( $120 \mu 1$ samples) were measured on a Radiometer blood gas system (BMS MK 111) at $37^{\circ} \mathrm{C}$. A continuous three lead electrocardiogram was used to record heart rate. Animal temperature was maintained with a thermal blanket (Corman Rupp Ind.) and recorded with a rectal probe connected to a telethermometer (Yellow Springs Inst. Co. Model 43TA). Animals were then allowed to stabilize following instrumentation.

\section{Experimental Protocol}

A) Control Group Each of eight animals underwent two serial blood flow determinations 30 minutes apart. Except for tracheostomy and cannulation, no surgical procedure was performed. The initial flow was measured after the injection of ${ }^{141}$ Ceriumlabelled microspheres, and 30 minutes later the second flow was measured with ${ }^{85}$ Strontium-labelled microspheres. During the experiment, the animals received an infusion of normal saline at $2 \mathrm{ml} / \mathrm{hr}$ via the right femoral, vein and respiratory rate and volume were adjusted to maintain blood gases within the physiological range.

B) Injury Group Five animals underwent a two level laminectomy at C7-T1, and then the first blood flow was measured with ${ }^{141}$ Cerium-labelled microspheres. Fifteen minutes later a 50 gram, one minute clip compression injury was performed at TI. ${ }^{12}$ Fifteen minutes after injury, during which time blood gases were assessed and any necessary ventilatory changes made, the second flow determination was made with ${ }^{85}$ Strontiumlabelled microspheres. The animals received a normal saline infusion at $2 \mathrm{ml} / \mathrm{hr}$ throughout the experimental period.

\section{Blood Flow Determination}

A) Isotope Preparation Radioactive microspheres, $15 \pm 3 \mu \mathrm{m}$ diameter (3M, New Brighton, Minnesota) were used for flow determinations. The microspheres were labelled with ${ }^{141}$ Cerium or ${ }^{85}$ Strontium with main gamma energy peaks of 320 and 514 $\mathrm{keV}$ respectively. The specific activity for both isotopes was 10 $\mathrm{mCi} / \mathrm{gm}$. Microspheres, obtained in the dry form, were weighed and then suspended in normal saline in a concentration of 45,000 microspheres/50 $\mu$ l. Tween-80 (3M, New Brighton, Minnesota) was used as a surfactant at a concentration of $0.05 \%$.

Standards for each isotope were prepared and used to determine the appropriate energy windows for the particular gamma counter utilized (Searle, model 1195). The counting efficiency for each isotope in its particular energy window was assumed to be $100 \%$, and overlapping counts from the other isotope were expressed as a percentage to develop an equation for calculating from the raw counts, those counts originating from a specific isotope. ${ }^{25-27}$

B) Microsphere Injection Prior to each flow determination, the microsphere solution was shaken by a Vortex mixer (Scientific Industries Inc., Model k-500-1), and a $100 \mu 1$ sample withdrawn with a micropipette. This sample was then injected into a length of PE 100 tubing, one end of which was connected to a saline-filled syringe attached to an infusion pump (Sage, Model $351)$ and the other end attached to the left ventricular cannula.

The arterial reference sample technique was used for measuring blood flow ${ }^{14}$ with the reference sample aspirated by a pump (Harvard, model 901) into a segment of PE100 tubing from the left femoral artery. Withdrawal began 15 seconds before microsphere injection, and was maintained at a rate of 0.393 $\mathrm{ml} / \mathrm{sec}$ for 90 seconds. The microspheres were injected by the infusion pump into the left ventricle at a rate of $0.05 \mathrm{ml} / \mathrm{sec}$ for 12 seconds. At the end of the 90 second withdrawal period, the reference blood specimen was flushed with $5 \mathrm{ml}$ of normal saline into a test tube for isotope counting.

C) Specimen Preparation and Treatment After the second microsphere injection in both groups, the animals were sacrificed with an intravenous injection of $\mathrm{KCl}$, and the spinal cord was removed via a complete $\mathrm{Cl}-\mathrm{L} 4$ laminectomy. The spinal cord was then placed on a $6 \mathrm{~cm}$ long template, containing four marked divisions each $1.5 \mathrm{~cm}$ long. The cord was placed so that the injury site rested at the midpoint of the second $1.5 \mathrm{~cm}$ division on the template. Any excess cervical or lumbar cord extending beyond the proximal and distal ends of the template were excised. The cord was then cut into 4 segments according to the division markings on the template, and designated: cervical, cervical-thoracic, thoracic and lumbar segments. The injury site was always located at the midpoint of the cervical-thoracic segment. Each segment was then placed in a pre-weighed counting tube and reweighed. The cerebral and cerebellar hemispheres, lungs, heart, spleen and kidneys were also removed, and similarly prepared. The position of the left ventricular catheter was determined prior to removal of the heart.

The specimens were then placed in a gamma counter (Searle, model 1195 ) and counted in both the ${ }^{141}$ Cerium and ${ }^{85}$ Strontium windows. A minimum of 10,000 total counts were accumulated in each channel to minimize counting errors. ${ }^{26.27}$

D) Flow Calculations and Statistical Analysis All calculations and statistical analyses were performed with a Wylbur text editor and the Statistical Analysis System at the University of Toronto Computing Centre. Paired T-tests were used on all flow, blood pressure and $\mathrm{CO}$ measurements within the control 
Table 1: Hemodynamic Parameters *

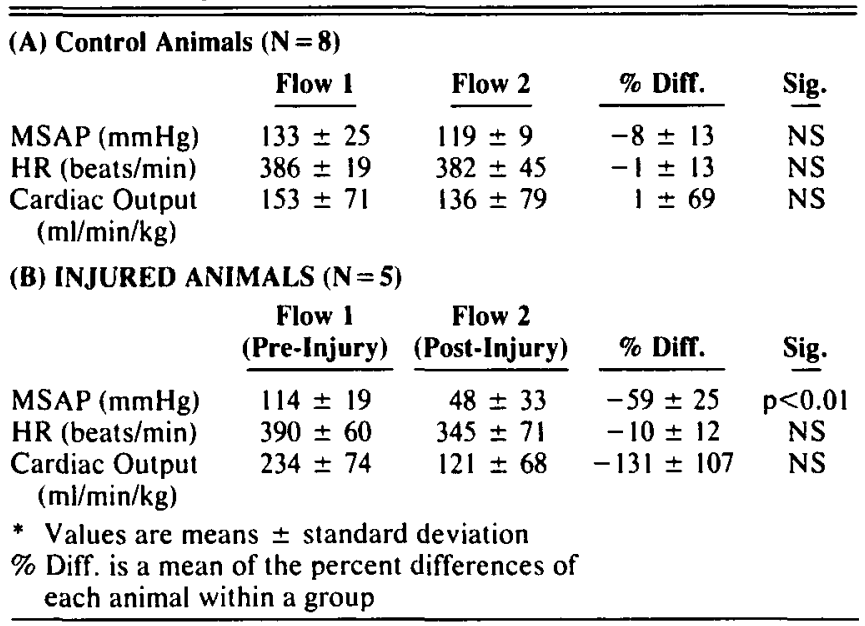

\begin{tabular}{|c|c|c|c|c|}
\hline \multicolumn{5}{|c|}{ (A) CONTROL ANIMALS $(N=8)$} \\
\hline & Flow 1 & Flow 2 & \% Diff. & Sig. \\
\hline $\begin{array}{l}\mathrm{pH} \\
\mathrm{pCO}_{2}(\mathrm{mmHg}) \\
\mathrm{p0}_{2}(\mathrm{mmHg}) \\
\text { Temperature }\left({ }^{\circ} \mathrm{C}\right)\end{array}$ & $\begin{aligned} 7.41 & \pm 0.04 \\
36.1 & \pm 1.6 \\
134 & \pm 22 \\
36.7 & \pm 1.2\end{aligned}$ & $\begin{aligned} 7.41 & \pm 0.03 \\
32.7 & \pm 2.3 \\
140 & \pm 24 \\
37.2 & \pm 0.9\end{aligned}$ & $\begin{aligned} 0 & \pm 0 \\
-10 & \pm 5 \\
3 & \pm 15 \\
1 & \pm 2\end{aligned}$ & $\begin{array}{c}\text { NS } \\
\mathrm{p}<0.01 \\
\text { NS } \\
\text { NS }\end{array}$ \\
\hline \multicolumn{5}{|c|}{ (B) INJURED ANIMALS $(\mathrm{N}=5$ ) } \\
\hline & $\begin{array}{c}\begin{array}{c}\text { Flow } 1 \\
\text { (Pre-Injury) }\end{array} \\
\end{array}$ & $\begin{array}{c}\text { Flow } 2 \\
\text { (Post-Injury) } \\
\end{array}$ & $\%$ Diff. & Sig. \\
\hline $\begin{array}{l}\mathrm{pH} \\
\mathrm{pCO}_{2}(\mathrm{mmHg}) \\
\mathrm{pO}_{2}(\mathrm{mmHg}) \\
\text { Temperature }\left({ }^{\circ} \mathrm{C}\right)\end{array}$ & $\begin{aligned} 7.40 & \pm 0.04 \\
35.2 & \pm 0.9 \\
137 & \pm 17 \\
37.5 & \pm 0.7\end{aligned}$ & $\begin{aligned} 7.27 & \pm 0.11 \\
35.7 & \pm 1.5 \\
136 & \pm 18 \\
36.7 & \pm 1.4\end{aligned}$ & $\begin{array}{l}-2 \pm 1 \\
2 \pm 4 \\
0 \pm 0 \\
-2 \pm 3\end{array}$ & $\begin{array}{c}p<0.05 \\
\text { NS } \\
\text { NS } \\
\text { NS }\end{array}$ \\
\hline \multicolumn{5}{|c|}{$\begin{array}{l}\text { * Values are means } \pm \text { standard deviation } \\
\% \text { Diff. is a mean of the percent differences of } \\
\text { each animal within a group. }\end{array}$} \\
\hline
\end{tabular}

Table 3: Regional Organ Blood Flow * $(\mathrm{ml} / \mathrm{gm} / \mathrm{min})$

\begin{tabular}{|c|c|c|c|c|}
\hline \multicolumn{5}{|c|}{ (A) CONTROL ANIMALS $(\mathrm{N}=8)$} \\
\hline Organ & Flow 1 & Flow 2 & \% Diff. & Sig. \\
\hline Heart & $5.3 \pm 1.4$ & $5.4 \pm 2.0$ & $7 \pm 47$ & NS \\
\hline L Lung & $1.0 \pm 1.5$ & $0.6 \pm 0.5$ & $28 \pm 130$ & NS \\
\hline R Lung & $0.9 \pm 1.6$ & $0.5 \pm 0.5$ & $37 \pm 142$ & NS \\
\hline Spleen & $1.3 \pm 1.0$ & $1.3 \pm 1.1$ & $2 \pm 46$ & NS \\
\hline L Kidney & $3.0 \pm 0.6$ & $2.3 \pm 1.1$ & $-21 \pm 40$ & NS \\
\hline R Kidney & $2.5 \pm 0.8$ & $2.0 \pm 1.2$ & $-14 \pm 48$ & NS \\
\hline \multicolumn{5}{|c|}{ (B) INJURED ANIMALS $(\mathrm{N}=5)$} \\
\hline Organ & $\begin{array}{c}\text { Flow } 1 \\
\text { (Pre-Injury) }\end{array}$ & $\begin{array}{c}\text { Flow } 2 \\
\text { (Post-Injury) }\end{array}$ & $\%$ Diff. & Sig. \\
\hline Heart & $3.3 \pm 1.9$ & $3.2 \pm 1.3$ & $7 \pm 35$ & NS \\
\hline L Lung & $0.7 \pm 0.9$ & $0.3 \pm 0.5$ & $-29 \pm 78$ & NS \\
\hline R Lung & $0.8 \pm 0.9$ & $0.4 \pm 0.6$ & $-11 \pm 136$ & NS \\
\hline Spleen & $0.6 \pm 0.3$ & $0.3 \pm 0.2$ & $-60 \pm 29$ & $\mathrm{p}<0.01$ \\
\hline L Kidney & $2.2 \pm 0.6$ & $1.2 \pm 0.7$ & $-46 \pm 23$ & $p<0.02$ \\
\hline R Kidney & $1.9 \pm 1.0$ & $1.0 \pm 0.5$ & $-41 \pm 28$ & NS \\
\hline \multicolumn{5}{|c|}{$\begin{array}{l}\text { * Values are means }+ \text { standard deviation } \\
\% \text { Diff. is a mean of the percent differences of } \\
\text { each animal within a group. }\end{array}$} \\
\hline
\end{tabular}

and injury groups, whereas T-tests were used between experimental groups. Each percent difference represents the mean of the percent differences of each animal within the group in question.

\section{RESUltS}

In the control group, there were no significant changes in MSAP, CO or heart rate between the two flow determinations, but in the injury series, MSAP decreased by $59 \%(p<0.01)$ following clip compression injury (Table 1). Although the $\mathrm{CO}$ in the injured series fell by $131 \%$, this difference was not significant. Isolated changes in the arterial blood gases were noted in both groups (Table 2). For example, the $\mathrm{pCO}_{2}$ fell to 32.7 between the two flows in the control group, whereas $\mathrm{pH}$ was significantly lower after injury $(\mathrm{p}<0.05)$. This post-injury fall in $\mathrm{pH}$ produced a $\mathrm{pH}$ significantly lower than that of the control group $(\mathrm{p}<0.05)$.

Regional organ blood flow values are noted in Table 3 . In the control series, there were no significant differences between the two flows, whereas in the injured animals, there were

Table 4: Spinal Cord Blood Flow * (ml/100gm/min)

(A) CONTROL ANIMALS ( $\mathrm{N}=8$ )

\begin{tabular}{|c|c|c|c|}
\hline Region & Flow 1 & Flow 2 & $\%$ Diff. \\
\hline Cervical & $66 \pm 16$ & $68 \pm 16$ & $10 \pm 47$ \\
\hline Cerv-Thor & $54 \pm 10$ & $55 \pm 14$ & $6 \pm 43$ \\
\hline Thoracic & $53 \pm 16$ & $48 \pm 16$ & $-6 \pm 31$ \\
\hline Lumbar & $66 \pm 15$ & $66 \pm 17$ & $4 \pm 37$ \\
\hline
\end{tabular}

(B) INJURED ANIMALS $(\mathrm{N}=5)$

\begin{tabular}{|c|c|c|c|c|}
\hline Region & $\begin{array}{c}\text { Flow } 1 \\
\text { (Pre-Injury) }\end{array}$ & $\begin{array}{c}\text { Flow 2 } \\
\text { (Post-Injury) }\end{array}$ & $\%$ Diff. & Sig. \\
\hline Cervical & $79 \pm 18$ & $41 \pm 22$ & $-49 \pm 23$ & $p<0.01$ \\
\hline Cerv-Thor & $56 \pm 18$ & $28 \pm 17$ & $-51 \pm 26$ & $\mathrm{p}<0.02$ \\
\hline Thoracic & $41 \pm 10$ & $34 \pm 13$ & $-16 \pm 25$ & NS \\
\hline Lumbar & $66 \pm 17$ & $50 \pm 22$ & $-21 \pm 30$ & NS \\
\hline \multicolumn{5}{|c|}{$\begin{array}{l}\text { * Values are means } \pm \text { standard deviation } \\
\% \text { Diff. is a mean of the percent differences of } \\
\text { each animal within a group. }\end{array}$} \\
\hline
\end{tabular}

Table 5: Brain Blood Flow $(\mathrm{ml} / 100 \mathrm{gm} / \mathrm{min})$

\begin{tabular}{|c|c|c|c|}
\hline \multicolumn{4}{|c|}{ (A) CONTROL ANIMALS $(N=8)$} \\
\hline Region & Flow 1 & Flow 2 & $\%$ Diff. \\
\hline $\begin{array}{l}\text { L Cerebrum } \\
\text { R Cerebrum } \\
\text { L Cerebellum } \\
\text { R Cerebellum }\end{array}$ & $\begin{array}{r}78 \pm 21 \\
70 \pm 27 \\
115 \pm 42 \\
124 \pm 34\end{array}$ & $\begin{aligned} 81 & \pm 15 \\
78 & \pm 18 \\
120 & \pm 48 \\
130 & \pm 30\end{aligned}$ & $\begin{aligned} 6 & \pm 13 \\
17 & \pm 22 \\
9 & \pm 39 \\
18 & \pm 58\end{aligned}$ \\
\hline
\end{tabular}

(B) INJURED ANIMALS $(\mathbf{N}=5)$

\begin{tabular}{|c|c|c|c|c|}
\hline gi & $\begin{array}{c}\text { Flow 1 } \\
\text { (Pre-Injury) }\end{array}$ & $\begin{array}{c}\text { Flow } 2 \\
\text { (Post-Injury) }\end{array}$ & \% Diff. & Sig. \\
\hline $\begin{array}{l}\text { Cerebrum } \\
\text { Cerebrum } \\
\text { Cerebellum } \\
\text { Cerebellum }\end{array}$ & $\begin{aligned} 64 & \pm 19 \\
53 & \pm 14 \\
126 & \pm 28 \\
142 & \pm 56\end{aligned}$ & $\begin{array}{l}49 \pm 20 \\
17 \pm 29 \\
71 \pm 28 \\
60 \pm 35\end{array}$ & $\begin{array}{l}-25 \pm 19 \\
-71 \pm 43 \\
-44 \pm 22 \\
-56 \pm 26\end{array}$ & $\begin{array}{l}p<0.05 \\
p<0.05 \\
p<0.02 \\
p<0.02\end{array}$ \\
\hline
\end{tabular}

* Values are means \pm standard deviation

$\%$ Diff. is a mean of percent differences of each animal within a group. 
significant decreases in flow to the spleen and left kidney after injury.

SCBF measured 30 minutes apart in the control series did not differ significantly (Table 4). However, following spinal cord injury, SCBF fell $51 \%$ in the cervical-thoracic junction segment containing the injury site $(p<0.02)$, and in the cervical region, SCBF also fell significantly $(49 \%, \mathrm{p}<0.01)$. Although SCBF decreased in the thoracic and lumbar segments, these changes were not significant (Table 4).

Although flow did not change in the cerebral or cerebellar hemispheres in the control series, there were marked decreases in cerebral and cerebellar blood flows following clip compression injury, with the decline being more pronounced in the right cerebral and right cerebellar hemispheres (Table 5).

\section{Discussion}

Radioactive microspheres have been used in larger animals (dogs, sheep) to perform repeated SCBF determinations in the same animal. ${ }^{7-10}$ The distinct advantage of such a technique is that each animal serves as its own control. To date, there have been no reports of the use of microspheres for SCBF studies in rats. The injury model most frequently used in our laboratory is the clip compression injury in the rat, ${ }^{12}$ and similar small animal injury models are being used increasingly elsewhere. Thus, a simple, cost-effective technique of obtaining multiple blood flow determinations in the rat would be advantageous.

Since microspheres were first introduced in the late 1960's for measurement of uterine blood flow, ${ }^{28-30}$ the technique has been used to study $\mathrm{CO}$, regional $\mathrm{CO}$ distribution, and blood flow in a variety of animals. ${ }^{31-33}$ For large animals, Buckberg et $\mathrm{al}^{34.35}$ have determined the minimum number of spheres required per sample to reduce the experimental error, and have also cautioned about the maximum number of microspheres which can be injected before capillary bed occlusion by microspheres disturbs hemodynamic performance. To date, the oniy guidelines for the rat have been reported by Tsuchiya et $\mathrm{al}^{22}$ who determined that $200,00015 \mu \mathrm{m}$ microspheres could be injected before adverse systemic effects are noted. Studies have not been done to precisely determine the minimal number of spheres per sample in the rat which provide a small experimental error, but 200 microspheres per sample has been suggested. ${ }^{22}$ To achieve a minimum number of 200 microspheres in each of the four segments of the spinal cord, the total spinal cord would have had to receive at least 800 microspheres. Given a percent $\mathrm{CO}$ distribution of approximately $1.5 \%,{ }^{9}$ then approximately 54,000 microspheres would have had to be injected to achieve this minimal microspheres per sample requirement. However, because of the reduced flow status known to occur following spinal cord injury, ${ }^{1-5}$ it was felt that a larger number of microspheres should be injected. Given that a total injection of more than 200,000 microspheres might compromise the hemodynamics of the rat, ${ }^{22}$ we limited the number of injections to two and the number of microspheres to 90,000 per injection. It was felt that this number would be sufficent to minimize the experimental error in flow determinations, ${ }^{25.34 .35}$ although, the large standard deviations in the current data suggest that a larger number of microspheres should have been used. Clearly, an accurate study needs to be done to determine the minimal number of microspheres required per spinal cord sample to reduce the experimental error.
In the control animals, the two flow studies 30 minutes apart, showed no changes in flow to the spinal cord, brain or major organs. These results verify the reproducibility of the technique in small animals to measure two flows within the same animal.

After clip compression injury, there were significant decreases in SCBF and in cerebral and cerebellar flow. Although CO decreased 15 minutes following experimental spinal cord injury, the change was not statistically significant. It is possible that a true drop in $\mathrm{CO}$ following spinal cord injury has been missed due to the small number in the injured group of animals $(n=5)$ and the large standard deviations encountered. A similar finding was reported by Tibbs et al, ${ }^{36.37}$ who noted a non-significant drop in $\mathrm{CO}$ in dogs following spinal cord transection. This maintenance of $\mathrm{CO}$ is somewhat surprising considering the decrease in sympathetic stimulation following cervical cord injury or transection. . $^{9.36 .37}$

The posttraumatic decline in SCBF in the present experiment occurred in the cervical-thoracic junction segment containing the site of clip compression injury, as well as in the adjacent cervical segment which extended up to $2.25 \mathrm{~cm}$ away from the injury site. It should be noted that a compression injury with a clip whose blades have a width of $1 \mathrm{~mm}$, has resulted in ischemia in a segment of cord extending from 0.75 to $2.25 \mathrm{~cm}$ from the injury site. Despite these large $1.5 \mathrm{~cm}$ segments of the cord, the microsphere technique was able to detect a drop in SCBF. It should be noted however that the SCBF measurements represent average flow values for the entire 1.5 $\mathrm{cm}$ segments, and do not represent regional SCBF. Changes in $\mathrm{SCBF}$ in smaller regions of the cord within each $1.5 \mathrm{~cm}$ segment, could be missed due to the effect of averaging. Smaller segments could not be studied because of the restriction imposed by the necessity to limit the total injected to less than 200,000 microspheres. Regional blood flow techniques such as autoradiography are much better suited for examining smaller regions of the cord if more discrete changes in SCBF are being studied. Although SCBF declined slightly in the thoracic and lumbar segments, the changes were not significant (Table 4). It is of interest that SCBF was maintained in these areas remote from the cord, despite a dramatic decline in MSAP to $48 \mathrm{mmHg}$ ( $p<0.01$, Table 1 ), indicating that autoregulation remained intact in most areas of the spinal cord remote from the injury site.

The decline in SCBF demonstrated following cord injury is consistent with that found by others. ${ }^{1-5.11}$ The drop in SCBF is likely due to a variety of reasons including vasospasm intravascular thrombosis or hypotension in an area devoid of normal autoregulation. ${ }^{1.4-6.40}$ Large areas of hemorrhage may also contribute to ischemia. ${ }^{41}$ It is of interest to note that SCBF was decreased in a segment which was $7.5 \mathrm{~mm}$ away from the $1 \mathrm{~mm}$ wide clip compression site. The mechanism for this remote change in SCBF is unknown, but again, a change in autoregulation or excessive hemorrhage may play a role. The mechanism by which these remote SCBF changes develop deserves further study, because of the possible deliterious effect on clinical recovery which might occur in cord injured patients.

The organ blood flow values were very similar to those reported by others ${ }^{17,20,40}$ whereas the $\mathrm{CO}$ values were slightly lower than others. ${ }^{9.17 .20 .38}$ If the percent $\mathrm{CO}$ distributions are compared to previous studies ${ }^{14,16-20.22 .24}$ the current results are higher, particularly in the heart. The explanation for the slightly lower $\mathrm{CO}$ values is not known, but it may have been due 
to an overestimation of the number of spheres injected into the left ventricle. This might have been due to excessive adhesion of spheres to the tubing or injection pipettes, even though the radioactivity in the pipettes and tubing was also included by placing them in the gamma counter. However, the technique was consistent throughout the experiment, and so relative changes in $\mathrm{CO}$ remain accurate.

Marked decreases in cerebral and cerebellar flow were detected following spinal cord injury (Table 5). The fall in cerebral and cerebellar blood flow on the right side, particularly the $71 \%$ decline in the right cerebral hemisphere, may be in part due to the occlusion of the right carotid artery to permit left ventricular cannulation. However, the decline in MSAP to $48 \pm 33 \mathrm{~mm} \mathrm{Hg}$ may have resulted in perfusion pressures below the range of autoregulation for certain animals. It would be beneficial to study the changes in cerebral and cerebellar blood flow following spinal cord injury at different levels of posttraumatic MSAP to investigate whether or not cerebral autoregulation remains intact after cord injury.

The radioactive microsphere technique has been shown to be useful for measuring SCBF, organ blood flow and $C O$ in the rat. The technique is simple, inexpensive, reproducible and capable of detecting changes in SCBF following spinal cord injury. It will provide a useful tool for the continued investigation of spinal cord ischemia following cord injury in the rat.

\section{ACKNOWLEDGEMENTS}

This study was supported by the Medical Research Council of Canada, Grant No. Mt 4046. Dr. M.C. Wallace was a Medical Research Council Fellow during the course of this research. The authors are grateful to Mr. I. Piper, Mrs. L. Marmash, Mrs. E. Forsythe and Miss M. Vespa for their assistance during this project.

\section{REFERENCES}

1. Dolan EJ, Tator $\mathrm{CH}$. The effect of blood transfusion, dopamine and gamma hydroxybutyrate on post-traumatic ischemia of the spinal cord. J Neurosurg 1982; 56: 350-358.

2. Kobrine AJ, Doyle TF. Martins AN. Spinal cord blood flow in the Rhesus monkey by the hydrogen clearance method. Surg Neurol 1974; 2: 197-200

3. Rivlin AS, Tator $\mathrm{CH}$. Regional spinal cord blood flow in rats after severe cord trauma. J Neurosurg 1978; 49: 844-853.

4. Senter HJ, Venes JL. Altered blood flow and secondary injury in experimental spinal cord trauma. J Neurosurg 1978; 49: 569-578.

5. Senter HJ, Venes JL. Loss of autoregulation and post-traumatic ischemia following experimental spinal cord trauma. J Neurosurg 1979; 50: 198-206.

6. Sandler AN, Tator, $\mathrm{CH}$. Regional spinal cord blood flow in primates. J Neurosurg 1976; 45: 630-646.

7. Del Masestro RF, Schosser R, Agerup B. Multiple cerebral and spinal cord blood flow measurements using the radioactive microsphere method. Bibliothica Anat 1979; 18: 201-203.

8. Hales JRS, Yeo JD, Stabback S, Fawcett AA, Kearns R. Effects of anaesthesia and laminectomy on regional spinal cord blood flow in conscious sheep. J Neurosurg 1981; 54: 620-626.

9. Marcus ML. Heistad DD, Ehrhardt JC, Abboud FM. Regulation of total and regional spinal cord blood flow. Circ Res 1977;41: 128-134.

10. Smith Dr, Smith JH, Raijoub Rk. Measurement of spinal cord blood flow by the microsphere technique. Neurosurg 1978; 2 : 27-30.

11. Brodkey JS, Richards DE. Blasingame BS. Nulsen FE. Reversible spinal cord trauma in cats. Additional effects of direct pressure and ischemia. J Neurosurg 1972; 37: 591-593.

12. Rivlin AS, Tator $\mathrm{CH}$. Effect of duration of acute spinal cord compression in a new acute cord injury model in the rat. Surg Neurol 1978; 9: 39-43.
13. Gjedde A, De la Monte SM, Caronna JJ. Cerebral blood flow and oxygen consumption in rat, measured with microspheres or Xenon. Acta Physiol Scand 1977; 100: 277-281.

14. Malik AB, Kaplan JE. Saba TM. Reference sample method for cardiac output and regional blood flow determinations in the rat. J Applied Physiol 1976; 40: 472-475.

15. Malik AB, Krasney JA, Royce GJ. Respiratory influence on the total and regional cerebral blood flow responses to intracranial hypertension. Stroke 1977: 8: 243-240.

16. McDevitt DG, Nies AS. Simultaneous measurement of cardiac output and its distribution with microspheres in the rat. Cardiovasc Res 1976; 10: 494-498.

17. Mendell PL, Hollenberg NK. Cardiac output distribution in the rat: Comparison of rubidium and microsphere method. AM J Physiol 1971; 221: 1617-1620.

18. Nishiyama K, Nishiyama A. Frohlich ED. Regional blood flow in normotensive and spontaneously hypertensive rats. Am J Physiol 1976; 230: 691-698.

19. Rakusan K, Blahitka J. Cardiac output distribution in rats measured by injection of radioactive microspheres via cardiac puncture. Can J Physiol Pharmacol 1974: 52: 230-235.

20. Sasaki Y, Wagner HN Jr. Measurement of the distribution of cardiac output in unanaesthetized rats. J Applied Physiol 1971: 30: 879-884.

21. Seifert J, Lob G, Probst J, Brendel W. Microcirculation and blood volume in rats before and after spinal cord injury. Paraplegia 1979; 17: 436-440.

22. Tsuchiya M, Ferrone RA, Walsh GM. Frohlich ED. Regional blood flows measured in conscious rats by combined Fick and microsphere methods. Am J Physiol 1978: 235: H357-H360.

23. Tsuchiya M, Walsh GM, Frohlich ED. Systemic hemodynamic effects of microspheres in conscious rats. Am J Physiol 1977: 233: H617-H261.

24. Vetterlein F, Halfter R. Schmidt G. Regional blood flow determination in rats by the microsphere method during IV infusion of vasodilating agents. Drug Research 1979; $29: 747-751$.

25. Dole WP, Jackson DL. Roseblatt JI. Thompson WH. Relative error and variability in blood flow measurements with radiolabelled microspheres. Am J Physiol 1982: 243: H371-H378.

26. Mernagh JR, Spiers EW, Addiseshiah M. The measurement of radioactive microspheres in biological samples. Phys Med Biol 1976; $21: 646-640$.

27. Quimby EH, Feitelberg S. Radioactive isotopes in medicine and biology. Basic Physics and Instrumentation. 1963: 2nd ed. Philadelphia: Lea \& Febiger.

28. Domenech RJ, Hoffman JIE, Noble MIM, Saunders KM, Henson JR, Subijanto S. Total and regional coronary blood flow measured by radioactive microspheres in conscious and anesthetized dogs. Circ Res 1969: 25: 581-596.

29. Makowski EL, Meschia G, Droegmueller W, Battaglia FC. Measurement of umbilical arterial blood flow to the sheep placenta and fetus in utero. Circ Res 1968; 23: 623-631.

30. Rudolph AM, Heymann MA. The circulation of the fetus in utero: methods for studying distribution of blood flow, cardiac output and organ blood flow. Circ. Res 1967: 21: 163-184.

31. Hales JRS. Radioactive microsphere techniques for studies of the circulation. Clin \& Exp Pharm Physiol Suppl 1974; 1: 31-46.

32. Heistad DD, Marcus ML, Ehrhardt JC. Abboud FM. Effect of stimulation of carotid chemoreceptors on total and regional cerebral blood flow. Circ Res 1976: 38: 20-25.

33. Heistad DD, Marcus ML, Mueller S. Measurement of cerebral blood flow with microspheres. Arch Neurol 1977: 34: 657-659.

34. Buckberg GD. Studies of regional coronary flow using radioactive microspheres. Ann Thor Surg 1975; 20: 46-51.

35. Buckberg GD, Luck JC, Payne DB, Hoffman JIE, Archie JP. Fixler DE. Some sources of error in measuring regional blood flow with radioactive microspheres. J Applied Physiol 1971: 31: 598-604.

36. Tibbs PA, Young B, McAllister RG. Studies of experimental cervical spinal cord transection. Part I: Hemodynamic changes after acute cervical spinal cord transection. J Neurosurg 1979: 49: 558-562.

37. Tibbs PA, Young B, McAllister RG, Todd EP. Studies of experimental spinal cord transection. Part III: Effects of acute cervical 
THE CANADIAN JOURNAL OF NEUROLOGICAL SCIENCES

spinal cord transection on cerebral blood flow. J Neurosurg 1979; 50: 633-638.

38. Dolan EJ, Tator $\mathrm{CH}$, Endrenyi $\mathrm{L}$. The value of decompression for acute experimental spinal cord compression injury. J Neurosurg 1980; 53: 749-755.

39. Griffiths IR. Spinal cord blood flow in dogs. 2. The effect of the blood gases. J Neurol Neurosurg Psychiat 1973; 36: $42-49$.
40. Sandler AN, Tator $\mathrm{CH}$. Review of the measurement of normal spinal cord blood flow. Brain Res 1976; 118: 181-198.

41. Wallace $\mathrm{MC}$, Tator $\mathrm{CH}$, Frazee $\mathrm{P}$. The relationship between posttraumatic ischemia and hemorrhage in the injured rat spinal cord as shown by colloidal carbon angiography. Accepted for publication, Neurosurgery. 